\title{
EDUCAÇÃO, TRABALHO E TECNOLOGIA
}

\author{
Marcelo Lima ${ }^{1}$
}

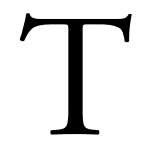

ese de doutoramento defendida no início dos anos 1990 na Universidade Estadual de Campinas (Unicamp) agora encontra o devido lugar com publicação pela Alínea. Traz estudo único e fundamental que se refere, de maneira atenta e profunda, às raízes da história da educação profissional no Brasil e no mundo. Entre os trabalhos que tratam historicamente as relaçóes trabalho e educação, este é certamente um dos mais ricos e completos, tanto do ponto de vista teórico quanto do historiográfico. Trata-se de obra relevante que se situa entre àquelas que fazem da historiografia e do materialismo histórico dialético instrumentos analíticos para compreensão da historicidade das relaçóes entre o Trabalho e Educação relativos à formação humana da classe operária.

Newton Antonio Paciulli Bryan, na obra Educação, Trabalho e Tecnologia (2015), traça uma trajetória da implantação da escola-fábrica em contraponto à fábrica-escola. Parte das críticas de Marx e de Hodgskin aos processos de (de) formação profissional, que se dão no interior do processo produtivo, advogando que os trabalhadores deveriam assumir o controle do seu saber e de sua formação.

A partir das colocaçóes do autor, percebemos que tanto na obra de Hodgskin como na de Marx a socialização do conhecimento é considerada como poderoso meio para a transformação social - Hodgskin criou a Mechanics Magazine e atuou no Mechanic's Institute de Londres, e Marx orientou o movimento operário internacional, organizado na associação internacional dos trabalhadores, no sentido de lutar por uma nova escola onde a educação intelectual e física se articulasse com o ensino tecnológico e o trabalho produtivo.

Infere que, para Hodgskin, na esteira do conceito de alienação de Marx, a destruição das relaçóes sociais em que o trabalhador detém a posse do instrumento de trabalho, garantida pela posse do saber, implica profundas e constantes transformaçóes nos processos de trabalho e nas formas de transmissão dos saberes. Bem antes da difusão do taylorismo no mundo, como nos informam os trabalhos de Braverman e de Charles Babage, já alertava que a divisão manufatureira do trabalho torna a sua execução cada vez mais simples, o que exige cada vez menos formação especial do trabalhador.

\footnotetext{
${ }^{1}$ Universidade Federal do Espírito Santo, Programa de Pós-Graduação em Educação, Departamento de Educação Política e Sociedade - Vitória (ES), Brasil. E-mail: marcelo.lima@ufes.br DOI: 10.1590/ES0101-73302016161231
} 
Nestes termos, segundo Bryan (2015), para Marx e Hodgskin, o que chamamos hoje de educação profissional sempre foi muito estratégico na luta capital versus trabalho. Nesse sentido, cabe aos trabalhadores controlar o desenvolvimento da estrutura da divisão do trabalho, que se dá por meio da manutenção de uma formação hominilateral e de uma atuaçáo politécnica. Tal processo engendraria a luta de classes. Considera que, mesmo antes do advento do taylorismo e do fordismo, na transição do artesanato para a produção industrializada, essas questóes já estavam colocadas, e que os trabalhadores, organizados por setores sindicais e produtivos, deveriam exercer o controle social da difusão dos saberes da e para a produção.

Outra grande contribuição do trabalho de Bryan é trazer uma contextualização histórica e uma descrição precisa do método Della-Vos, que revolucionou a aprendizagem dos ofícios. Antes desse método, não só na Rússia, mas também no mundo industrial desenvolvido, não havia modelo de aprendizagem que se colocasse como referência, tampouco método que se colocasse como alternativa e referência pedagógica transcendente ao ensino típico das corporaçóes de ofício (realizado no espaço doméstico) e à aprendizagem assistemática que se dava durante a produção (realizada na fábrica) - um problema que foi superado pelo método de Della-Vos.

A difusão do método através das exposiçōes mundiais encontrou um meio bastante receptivo nos Estados Unidos, constituído pela rápida criação de escolas técnicas industriais e de engenharia no último quarto do século XIX. Instituições como o Massachusetts Institute of Tecnology, o Stevens Institute of Tecnology e a Universidade de Washington organizaram seus nascentes cursos técnicos industriais e de engenharia tendo como base a experiência. Outras exposiçóes difundiram ainda mais o método russo: a exposição de Viena, em 1873, auxiliou sua difusão na Áustria e em estados alemães, onde foram fundadas escolas com oficinas concebidas espacialmente para operá-lo. Em Munique, as organizaçóes dos artesãos da cidade levantaram-se contra o método de Leipzig, que tem como base a confecção de objetos úteis, o que, de algum modo, colaborou para a adoção do método de Della-Vos de forma imune a restriçóes, porque produzia objetos sem valor mercantil e, logo, náo concorria com o artesanato (SMITH, apud BRYAN, 2015, p. 283).

Segundo Bryan (2015), esse método funda-se na aplicação da análise do ofício ao ensino do trabalho, posteriormente principiando pela divisão dos ofícios em subocupaçóes, tarefas e operaçóes que são organizadas e sequenciadas em ordem crescente de dificuldade. Nele, o aprendiz inicia sua aprendizagem pelo trabalho mais simples e, gradativamente, atinge o mais complexo.

Bryan (2015), no entanto, alerta que a organização do processo de ensino segundo os princípios analíticos não foi efetuada pela primeira vez por Della-Vos. Desde o lançamento das bases da didática moderna por Comênio, vários 
pedagogos já haviam empregado o princípio analítico para organizar o processo de ensino. No "alfabeto das formas", elaborado por Pestalozzi para a sistematização do ensino de desenho, já era utilizado o princípio da divisibilidade do objeto de ensino e sua organizaçáo em séries segundo a ordem crescente de dificuldade (BARNARD, apud BRYAN, 2015, p. 263). Nesse preâmbulo, o próprio DellaVos reconhece o trabalho pioneiro do engenheiro mecânico francês A. Clair, que havia organizado coleçóes de modelos de instrumentos "para ensinar segundo o modo clássico as diferentes operaçóes usadas no trabalho manual" (DELLA-VOS, apud BRYAN, 2015, p. 262).

Nota-se que a originalidade de Della-Vos não está, portanto, em utilizar o método analítico, mas em aplicá-lo ao ensino de ofícios. Della-Vos articulou seu método também de modo original ao ensino do desenho, considerado por excelência a linguagem da tecnologia, com a atividade prática em oficina baseada na reprodução de modelos de peças. Para o ensino da execução dessas tarefas, DellaVos orientou os instrutores da escola a elaborar séries de desenhos e modelos em madeira dispostos segundo uma ordem crescente de dificuldade.

Segundo um observador americano em 1893, o método é operado do seguinte modo:

1 - cada ofício ou parte do trabalho tem sua própria oficina de instrução separada; por ex.: joalheiro, torneagem de madeira, etc.; 2 - Cada oficina é equipada com tantos postos de trabalho e conjuntos de ferramentas quantos forem os alunos a receber a instrução ao mesmo tempo; 3 - as séries de modelos sáo arranjadas de acordo com a ordem crescente de dificuldade dos exercícios envolvidos, e devem ser fornecidos aos alunos na estrita sucessão em que forem arranjados; 4 - todos os modelos são feitos a partir de desenhos. Cópias de cada desenho são fornecidas em número suficiente para prover cada membro da classe com um desenho; 5 - os desenhos são feitos por alunos na classe elementar sob a direção de um professor, com quem o diretor das oficinas entre em acordo a propósito dos detalhes; 6 - a nenhum aluno é permitido começar um novo modelo até que ele tenha completado de modo aceitável o modelo prévio do curso; 7 - os primeiros exercícios serão aceitos se as dimensóes forem aproximadamente corretas e os exercícios posteriores devem possuir exatamente as dimensóes previstas. Portanto, as diferentes notas dadas a um estudante em diferentes períodos durante seu curso não expressam de modo absoluto, mas relativo, as qualidades de suas diferentes peças de trabalho; 8 - cada professor deve possuir mais conhecimentos da sua especialidade do que é necessário meramente para executar os exercícios de instrução. Deve praticar constantemente para que seu trabalho seja um exemplo de perfeição para seus alunos. Tal destreza aumenta a autoridade do professor. (BENETT, apud BRYAN, 2015, p. 269). 
Outro aspecto desenvolvido de maneira original e inédita por Bryan é o processo de implantação da aprendizagem sistemática no Brasil, que se inicia em 1916 na estrada de ferro no Rio de Janeiro. Posteriormente, na dácada de 1920, as Series Metódicas Ocupacionais foram combinadas com elementos da Organizacâo Racional do Trabalho e implementadas pelo engenheiro Roberto Mange, seu maior precursor. Assim como Della-Vos, mas com objetivos e ideologia diferentes, Mange combatia esse modelo de aprendizagem, que ele denominava "instrução comum", em contraponto ao que classificava como "instrução racional"; nesta, o tempo de formação no processo de trabalho era definido pelos mestres sem o estabelecimento de métodos formativos padronizados a partir da análise ocupacional, como ocorre nos processos de aprendizagem sistemática.

A criação de um lócus específico para a formação profissional também é advogada por vários autores. Bryan (2015) entende que, na aprendizagem sistemática, "condições especiais (são) criadas para que ocorra a aprendizagem (...)"; ou seja, "ao separar o espaço e o tempo dedicado à aprendizagem, ao instituir a figura do instrutor de ofícios com a função específica de ensinar" (ROLLE, apud BRYAN, 2015, p. 273), permitindo-se, assim, que o processo educativo se guie pelos objetivos do ensino, e não da produção.

No Brasil, o método tem sua versão taylorizada por Mange e incorporado às experiências pedagógicas preconizadas por ele, tendo o tempo de aprendizagem como um dos principais diferenciais entre os modelos de aprendizagem. Um aprendizado prático metódico baseado na decomposição simplificada do trabalho que se mostrou eficaz em formar, sem vícios e rapidamente, profissionais que ao produzirem geravam poucos erros e desperdícios.

\section{Referências}

BRYAN, N.A.P. Educação, Trabalho e Tecnologia. 1a ed. Campinas: Alínea, 2015.

Recebido em 16 de março de 2016.

Aprovado em 14 de setembro de 2016. 